\title{
RUPTURAS IDENTITÁRIAS NA PRODUCÃO ARTÍSTICA DE CINDY SHERMAN E YASUMASA MORIMURA
}

\section{IDENTITY RUPTURES IN THE ARTISTIC PRODUCTION OF CINDY SHERMAN AND YASUMASA MORIMURA}

Morimura Jacks Ricardo Selistre ${ }^{1}$ Rosa María Blanca² 


\section{Resumo}

Este artigo propõe uma análise queer das produções artísticas de Cindy Sherman e Yasumasa Morimura a fim de problematizar a inexistência de um sujeito original e único na contemporaneidade. A abordagem queer (BLANCA, 2011) permite desconstruir identidades fixas, proporcionando leituras plurais às obras de arte. Sherman e Morimura se apresentam como sujeitos instáveis, transformáveis e com identidades efêmeras, de modo que desestabilizam o sistema clássico de identificação. Nas suas produções os sujeitos se instalam no devir (des)identitário, (des)construindo-se constantemente. Através das produções de Sherman a linguagem do autorretrato é problematizada, questionando quais métodos de exposição do sujeito são possíveis para o autorretrato na arte contemporânea. Os sujeitos são problematizados na obra de Morimura através da estética camp que se alia ao exagero e à imitação, questionando a fixidez identitária e os processos naturais de construção dos sujeitos.

Palavras-chave: Cindy Sherman, Yasumasa Morimura, Identidades, Abordagem Queer.

\section{Abstract}

This article proposes a queer analysis of the artistic productions of Cindy Sherman and Yasumasa Morimura with the intent of question the lack of existence of a single and original individual in the contemporary society. The queer perspective allows to deconstruct a fix identity concept, providing a plural interpretation of art. Sherman and Morimura present themselves as changeable individuals with ephemeral identities in order to unstable the conventional gender identification system. Their productions are based on the process of an ever changing identity, to (de)construct themselves constantly. Throughout Sherman productions, the self-portrait language is analysed, questioning in what way can the self-portrait expose an individual in contemporary art. The individual is discussed in Morimura's work through the camp aesthetics, combined with the concepts of exaggeration and imitation, questioning the permanency of an identity and the natural processes in the construction of an individual.

Keywords: Cindy Sherman, Yasumasa Morimura, Identidades, Abordagem Queer.

ISSN: 2175-2346

1 jacksricardoselistre@gmail.com

2 artesubjetividades@gmail.com 


\section{Introdução}

Nos últimos anos percebeu-se a transformação dos paradigmas referentes aos estudos identitários através da globalização, que influenciou nesta mudança, mostrando que as teorias que discorrem sobre as identidades não são finitas, mas permanecem em processo. A mudança dos paradigmas identitários fez com que os sujeitos se modificassem, não se comportando mais como antigamente. A transitoriedade foi associada aos sujeitos contemporâneos, as possibilidades de si aumentaram. Os sujeitos alteraram as bases sociais das identidades através da efemeridade e da (des)construção de si. Com isso não se pensa mais em um sujeito estável, com uma identidade duradoura, hoje os sujeitos se encontram abertos a modificações devido às influências socioculturais que possibilitam a transitoriedade individual e coletiva. Assim o sujeito autodescobre-se em meio ao devir (des)identitário.

Busca-se uma abordagem queer ${ }^{1}$ para compreender as produções artísticas e as modificações identitárias a fim de explorar as subjetividades contemporâneas que se inscrevem na indeterminação e na dúvida, desconstruindo supostas certezas. Os sujeitos apresentam-se como migrantes, percorrendo as possibilidades identitárias. Neste sentido não há a busca por uma identidade contínua e duradoura, mas há a intenção do trânsito identitário, das possibilidades de si. Sugere-se a ruptura identitária através da descontinuidade, sendo essa uma atitude queer que proporciona sujeitos (des) identificados e subjetividades plurais que não se articulam com as hierarquias sociais pautadas pelas identidades. As teorias queer auxiliam a problematizar o sistema da arte e o sistema identitário, destacando-se contra os efeitos normalizadores da sociedade, dando brecha a leituras contra-hegemônicas. Neste sentido, os estudos queer desestabilizam a ordem normativa construtora das identidades e do sistema artístico, uma vez que sujeitos queer expressam resistência frente às imposições sociais, culturais e artísticas. A abordagem queer ${ }^{2}$ presente neste artigo questiona as identidades sexuais e os gêneros normativos que agem como regimes de verdade e de biopolítica (BOURCIER, 2011) a fim de permitir a emergência de sujeitos livres e transitórios, que não são moldados pelas imposições sociais identitárias de sexo/gênero, explorando assim a potencialidade artística e social de sujeitos (des)identificados.

Neste artigo, através de uma abordagem queer, analisa-se a obra Untitled \#408.2002 de Cindy Sherman e a obra Doublonnage (Marcel) de Yasumasa Morimura a fim de descentralizar o sujeito e de desestabilizar as identidades que atuam como métodos de regulação dos sujeitos. Esses artistas utilizam-se da fotografia a fim de explorar as possibilidades (des)identitárias dos sujeitos/as, colocando em xeque a estabilidade dos indivíduos e dos corpos, dos gêneros e das sexualidades. Suas produções ainda colocam em discussão os limites da arte contemporânea e de suas linguagens. De maneira que as fotografias ou os autorretratos que realizam podem

\footnotetext{
10 termo queer surge em meio aos anos 1970/80 nos Estados Unidos, sendo utilizado para humilhar sujeitos que não seguiam a heteronormatividade. 0 significado deste termo em inglês equivale a algo como estranho ou excêntrico. Entretanto o termo queer foi ressignificado pelos pelos sujeitos que outrora foram humilhados, transformando uma ofensa em empoderamento. 0 queer surge como um movimento social que questionava a imposição da heterossexualidade aos sujeitos e a normalização dos sujeitos e dos corpos. A ação de sujeitos queer baseia-se na expansão dos limites de pensamento, para que não se encontrem cerceados pelo cânone sexual fundamentado pelas forças de poder, de maneira que as práticas queer recusem explicações (RODDRIGUEZ, 2003). Posteriormente o queer adentra ao meio acadêmico destacando-se com as filósofas Glória Anzaldúa, Judith Butler, Eve Sedgwick, Paul B. Preciado, Sam Bourcier e Guacira Lopes Louro. Destaca-se que os movimentos e as teorias queer não questionam os sujeitos que encarnam a norma identitária (heterossexual), mas a ordem cultural e os jogos de poder que estabelecem a normalidade e a abjeção (PELÚCIO, 2014).

2 A abordagem queer permite analisar obras de arte por outras perspectivas que não se baseiam nos cânones identitários. Deste modo a abordagem queer permite perceber a instabilidade do sistema identitário e de gênero a fim de possibilitar leituras que não se restrinjam aos cânones comportamentais e às modalidades tradicionais de leitura das obras de arte e dos corpos, permitindo interpretações mais plurais que não se detenham aos cânones.
} 
ser amplamente discutidos enquanto linguagem artística, de modo a refletir sobre os limites e as fronteiras do autorretrato em uma concepção clássica do sujeito que se autofotografa mostrando a si mesmo/a, e do autorretrato contemporâneo. Sherman e Morimura transitam entre distintas estéticas e subjetividades. A estética camp ${ }^{3}$ é utilizada para analisar a produção de Yasumasa Morimura, a fim de suscitar uma interpretação queer às obras de arte, possibilitando o afastamento da lógica heterossexual, tensionando os limites entre o natural e o inatural através da artificialidade e do exagero na composição de suas obras, propondo uma subversão aos sujeitos socialmente idealizados.

\section{Identidades contemporâneas: a problemática do indivíduo}

A contemporaneidade proporciona identidades múltiplas, facetadas, por vezes destoantes e contraditórias. Este contexto gera a possibilidade de escolha a ser feita no grande leque das identidades contemporâneas, que diferentemente de outros momentos, admite e reconhece a mutabilidade da identidade individual, ou coletiva. Vive-se em um período que as transformações são constantes e que verdades absolutas são contestáveis.

A perenidade e a fixidez identitária já não é mais encarada como característica do indivíduo contemporâneo, visto que o pensamento de identidade cristalizada ficou ancorada no sujeito do iluminismo. De acordo com as ideias de Stuart Hall (2015) existem três concepções de identidade: do sujeito do iluminismo, do sujeito sociológico e do sujeito pós-moderno.

O sujeito do lluminismo possui uma identidade que se caracteriza pelo pensamento racional, nascendo com ele e permanecendo essencialmente contínua ao longo de sua vida. Esse sujeito é marcado pelo individualismo, pela centralidade do próprio eu, propondo a ideia de uma identidade fixa e imutável. Em contrapartida, a identidade do sujeito sociológico que se encaixa no mundo moderno, pode ser vista como interdependente, de maneira que sua identidade é formada pela interação com outras pessoas de seu entorno e com outras culturas, tornando-se cada vez mais expandido com a evolução das mídias. Já o sujeito pós-moderno é consequência das mudanças identitárias do sujeito sociológico, organiza-se através de uma identidade fragmentada. Ou seja, diferentemente dos sujeitos anteriores, o sujeito pós-moderno não possui uma identidade, mas sim várias identidades possíveis. É permitido que o sujeito pós-moderno explore as possibilidades identitárias a fim de formar-se enquanto pessoa, sendo esse um processo contínuo e incessável.

A possibilidade de trânsito identitário pode gerar a seguinte reflexão, nas palavras de Tomaz Tadeu (2016, p. 9 apud. CADAVA; CONNOR; NANCY 1991) "a questão não é mais agora quem é o sujeito', mas 'queremos ainda, ser sujeitos?', 'quem precisa do sujeito?'". Seguindo a linha de raciocínio pergunto-me: quem de fato precisa do sujeito e da identidade na contemporaneidade? Pode-se compreender o sujeito e a identidade como um termo que busca organizar e hierarquizar a sociedade, cada sujeito ocupa determinada posição social, cultural e econômica. Vê-se a categoria de

30 camp é uma estética da sensibilidade que se baseia no exagero e na inaturalidade. Se associa ao queer por posicionar-se contra as normatizações das sensibilidades contemporâneas (SOUZA, 2014), bem como propõe a subversão e a ironia aos modelos estéticos e políticos dominantes. 
sujeito como uma categoria que remete à organização e à ordem social identitária. O sujeito e a sua identidade são métodos disciplinares do poder, que nos engana e faz com que nos enganemos a nós mesmos/as (FOUCAULT, 1992), compreendendo construções sociais como naturais, sendo assim os únicos modelos a serem seguidos e por isso os estudos queer recusam a fixidez que essas categorias produzem (LOURO, 2004).

A identidade e seus valores hegemônicos podem ser contestados à medida que ela se solidifica nos conceitos de sexo, gênero e sexualidade, que são conceitos perturbados pela emergência cultural daqueles/as cujo gênero é incoerente e descontínuo (BUTLER, 2016, p. 43). Assim, com a descontinuidade e com a incoerência, o processo identitário hegemônico é desestruturado e novas teorias podem vir a compreender e questionar os estudos das identidades e as transformações sociais do sujeito.

Esses fatores de descontinuidade e incoerência são proporcionados pela pós-modernidade que oferece múltiplas escolhas ao indivíduo, podendo ele/a optar por mais de uma identidade, inclusive por identidades contraditórias, questionando a ideia de um sujeito centrado e fixo como a sociedade normativa idealiza. Com isso, pode-se entender uma ruptura ao sistema clássico do sujeito. Visto que o indivíduo pode ora possuir uma identidade, ora possuir outra, descartando assim as identidades que já não lhe conferem mais, podendo apresentar espectros de diferentes identidades ao mesmo tempo. Nessa nova concepção identitária, é possível afirmar que o indivíduo é efêmero e transitório, admitindo a existência de diferentes identidades em um mesmo sujeito, ou até mesmo a recusa a uma identidade específica.

A efemeridade da identidade pós-moderna pode suscitar a ideia do descartável, assim como tudo na pós-modernidade, de acordo com as ideias de Zygmunt Bauman (2012), em que relacionamentos e objetos possuem prazo de validade, nada mais é duradouro como se imaginava anteriormente. O sujeito pós-moderno busca insaciavelmente pela novidade e ele é constantemente bombardeado de novas informações, de novas culturas. Assim, busca novas identidades possíveis de serem assumidas.

As grandes transformações que perpassaram o mundo nas últimas décadas, sobretudo a globalização, fizeram com que as concepções identitárias do sujeito fossem transformadas ao longo do tempo. Cada identidade está de acordo com o período em que se viveu e com o paradigma vigente de cada época. Contudo, na pós-modernidade, observa-se a rápida transformação, não só identitária, mas também em aspectos sociais, políticos e culturais.

Partindo dos estudos identitários e das novas individualidades, a arte contemporânea mostra-se cada vez mais interessada em assuntos relacionados às subjetividades, tendo sido comum artistas produzirem suas obras relacionadas a contextos sociais, como a guerra, política, identidades e sexualidades. Os/as artistas não se posicionam de maneira neutra ou acrítica, mas enfatizam como a história e como as suas identidades influenciam na produção artística, tornando evidente que as identidades negras ou gays, por exemplo, afetam e (trans)formam a intenção da obra. Neste caso, o pessoal torna-se político (ARCHER, 2012) e artístico. Os temas já não são mais os mesmos, as fronteiras entre arte e vida são constantemente diluídas, vê-se a inter-relação de estudos, a arte não se serve somente da história da arte, mas de 
inúmeras disciplinas, como da filosofia, dos estudos queer e dos estudos de gênero. Possibilitando produções interdisciplinares, abordando temas de interesse social.

A efervescência do movimento LGBT nos anos 1980 na luta contra a AIDS foi importante para reformular o contexto artístico, surgindo obras que abordavam criticamente essa temática. 0 movimento e os estudos queer também se fizeram presentes como método de questionamento identitário. Produções e exposições abordavam e abordam as dissidências sexuais e identitárias. Levando ao público, através de obras de arte, novas perspectivas de sujeitos, como sujeitos ambíguos, assexuados e intersexuais. Sujeitos omitidos/as pelo sistema dominante nas artes e nas sociedades. Pensando nas novas perspectivas, artistas iniciaram uma produção que desloca o sujeito centrado, que problematiza os binarismos entre homem/ mulher, entre homo/heterossexualidade. Essas produções que contestam as normas suscitam novos pensamentos estéticos, filosóficos, além de novos corpos, paradigmas e possibilidades. O/a artista goza da autonomia de si, a produção de corpos e comportamentos é incessante, tanto na arte, quanto na sociedade.

\section{Sujeito Transformável na Produção de Cindy Sherman e Yasumasa Morimura}

Cindy Sherman e Yasumasa Morimura são artistas que exploram as possibilidades de si, projetando em suas obras também as possibilidades do outro/a. De maneira a questionar convenções identitárias e sociais, produzindo novas subjetividades que não se atrelam a modelos pré-determinados socialmente. O sujeito imutável é desestabilizado com as possibilidades de si, com as possibilidades de mudança, de negação e de ambiguidade. Essas mudanças são consequência de um intercâmbio constante consigo e com outrem, a cada momento o sujeito é reconstruído, encontrando-se em processo de construção e desconstrução permanentes.

Cindy Sherman é uma artista estadunidense que possui uma produção artística voltada para fotografias, nas quais a artista se posiciona em frente à câmera a fim de explorar outras identidades influenciadas por personagens de filmes ou de obras de arte, como pode ser evidenciado na série Film Still. É comum que a artista se (trans) figure a fim de compor suas personagens. A composição de suas fotografias conta com inúmeros elementos pré e pós fotográficos que fortificam a artificialidade na construção de sujeitos e identidades, destacando assim a transitoriedade identitária, tanto de suas personagens, quanto das sociedades contemporâneas, explorando assim o processo artificial de construção do sujeito.

A produção fotográfica auxilia a compreender a construção das identidades utilizadas pela artista, como pode ser evidenciado na obra Untitled \#408.2002 em que a artista utiliza maquiagens e peruca para construir sua personagem, assim pode-se entender o retrato fotográfico e as identidades como um prisma do artifício, não somente pelos termos técnicos, mas pela possibilidade de construção de máscaras que dissimulam a existência do sujeito original (FABRIS, 2003). Ainda pode-se questionar, qual seria o sujeito original? Aquele/a representado/a pela artista, ou o sujeito da artista Cindy Sherman? É possível discutir os limites filosóficos, técnicos e conceituais da linguagem artística utilizada, o autorretrato. Ainda pode-se discutir que $o$ 
sujeito original é deslocado para dar lugar a uma identidade artificial que suprime a individualidade em prol de um agrupamento identitário. Nesse sentido, problematiza-se a existência de um sujeito original, já que somos constantemente moldados pelas instâncias reguladoras. Na produção de Sherman, o sujeito original se desloca, perpassa cânones identitários, de maneira que permite a discussão dos limites entre sujeito original e artificial.

A produção de sujeitos faz com que a fronteira de identidade artificial e identidade original/natural e fixa se dissipe. Ainda com relação à questão de dissimular o sujeito original, pensando no autorretrato, essa não poderia ser considerada uma subversão às regras? Já que se nota uma recusa de se autoexibir, de se autorrevelar? (FABRIS, 2003), ou bem, pode-se compreender com a intenção em autorrevelar-se de maneira plural, através da produção de novos corpos e de novas subjetividades que passam a constituir o sujeito. Essa problematização acerca do sujeito, da identidade no autorretrato pode suscitar reflexões. Qual é o sujeito do autorretrato? Aquele que simplesmente fotografa a si mesmo, que se exibe à câmera, mostrando-se conforme o habitual? Ou seria permitido também aquele que se fotografa assumindo outras personagens, outras identidades? Produzindo um outro corpo dramatizado e exagerado que se apresenta a fim de colocar em colapso os sistemas canônicos das identidades e da linguagem artística do autorretrato. O que constituiria o autorretrato? Ou melhor, no que pode se constituir o autorretrato na arte contemporânea? Qual seria a real identidade do sujeito presente no autorretrato? Quem legitima tal identidade como verdadeira? Só uma identidade poderia ser permitida, ou são permitidas múltiplas identidades em um mesmo sujeito?

Ao explorar e questionar as linguagens artísticas chega-se a uma reflexão que possibilita novas miradas sobre um tema já conhecido. $O$ autorretrato pode ser concebido de ambas as formas citadas. Tanto por aquele/a que se autofotografa revelando a si mesmo/a, bem como aquele/a que se autofotografa representando-se através de um personagem, como Sherman e Yasumasa Morimura. A questão está no ato de posicionar-se em frente à câmera. $O$ real sujeito a aparecer não necessariamente precisa existir, afinal, existe um sujeito real/original? Os sujeitos se constituem através de um simulacro, são representações, imitações construídas socialmente. Neste sentido, distintos sujeitos são possíveis nessa linguagem. Pode-se compreender distintas perspectivas de autorretrato, o que não quer dizer que uma sobreponha-se à outra. Há espaço para aqueles/as que buscam mostrar-se a si mesmo/a, bem como há espaço para aqueles/as que utilizam maquiagens, roupas e assim transfiguram sua aparência física, suscitando assim um novo corpo e uma nova maneira de afirmar-se enquanto sujeito. Podendo sugerir, um autorretrato falso, enganador, mas o autorretrato nada mais é do que isso: um simulacro, uma ilusão, um engano (PACHECO, 2012). Assim como as identidades e o seu sistema, que se constituem como uma ilusão, um simulacro comportamental idealizado.

Ainda é possível refletir acerca da efemeridade identitária. O sujeito não possui mais uma identidade fixa, ele/a pode usufruir de inúmeras identidades/identificações a fim de formar-se enquanto sujeito. Essa possibilidade permite que nem sempre o sujeito e sua identidade sejam contínuos, por mais que o corpo seja o mesmo, sua identidade - visual ou não - é continuamente construída e transformada. Os sujeitos encontram-se não na fixidez, mas no devir identitário. 
As diferentes personagens de Sherman possibilitam uma ruptura com o modo essencialista de pensar as identidades. A artista mostra que na contemporaneidade é possível que os sujeitos assumam inúmeras identidades a fim de se constituir enquanto indivíduos, e mostra que essas identidades e o constituir-se enquanto indivíduo não é algo fixo, mas mutável e contínuo, algo em devir que se encontra em constante transformação. Embora a sua produção proponha a ruptura com as questões identitárias clássicas, vê-se que suas personagens se configuram como produtos do olhar masculino, cujos papéis são determinados por ele, propondo que o conceito mulher é um efeito do outro (JONES, 1997; FABRIS, 2003). Assim como o conceito de identidade, que é determinado pelo outro, como método de significação de pessoas e de comportamentos.

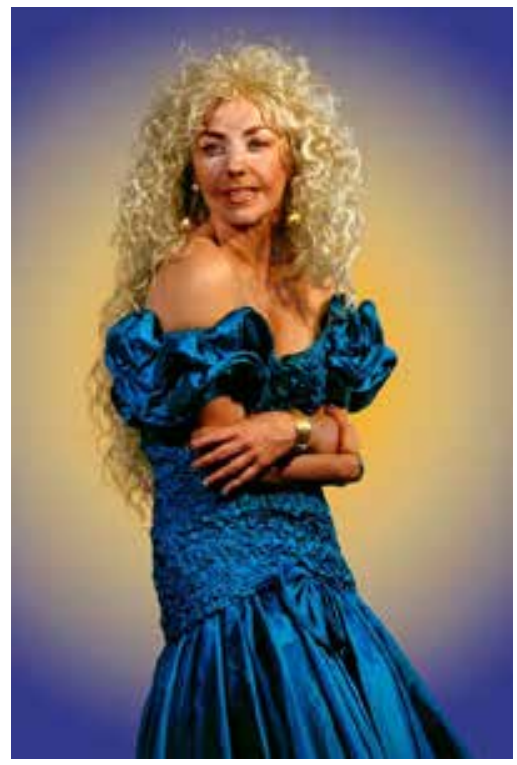

Fig. 1 - Cindy Sherman, Untitled \#408.2002, Chromogenic color print, 137 x 91cm, 2012 ,

Collection od Melva Bucksbaum and Raymond J. Learsy.

Fonte: https://www.moma.org/interactives/exhibitions/2012/cindysherman/lib/uploads/G05A01Untitled-408.2002_large.jpg

Yasumasa Morimura é um artista japonês que produz suas obras através do apropriacionismo ${ }^{4}$. Em sua produção o artista reinterpreta visualmente obras e fotografias icônicas, onde o próprio artista se posiciona como a personagem principal da obra em questão. Ao modificar a personagem das obras, sua prática artística solapa o sistema tradicional da arte, as identidades canônicas e o binarismo de gênero masculino/feminino, isso pode ser percebido à medida que o artista se representa como Che Guevara ou como Marilyn Monroe, ou bem quando se apropria de uma fotografia de Man Ray (Figura 2 - Doublonnage (Marcel). Ao apresentar-se em ambos gêneros o artista explora possibilidades corpóreas, indeterminando seu gênero e rompendo com o sistema binário de identificação, operando como sujeito de gênero ambíguo e mutável. Neste sentido, a sua produção artística constitui-se através do trânsito identitário e de gênero. Razão pela qual o artista se distancia do cânone heteronormativo, uma vez que para este sistema deve-se escolher entre o masculino ou feminino, impossibilitando a existência de corpos ambíguos e fronteiriços (ANZALDÚA, 1987).

4 Como apropriacionismo, pode-se entender uma atitude artística desenvolvida por Marcel Duchamp no início do século XX, e mais recentemente com Sherrie Levine, que utilizou-se de obras de arte já existentes a fim de compor as suas próprias. Neste caso, apropriacionistas (re)significam a obra citada, alterando seu contexto e desconstruindo significados tradicionais (DEMPSEY, 2010). Destacam-se Louise Lawler, Jeff Wall e Rosangela Rennó. 
A desconstrução das identidades continua através da apropriação artística que esse artista realiza, através de maquiagens, iluminação e processos fotográficos que permitem que ele se represente tanto em personagens masculinos quanto femininos. Suas criações questionam a fixidez identitária e a naturalidade das regras de gênero prescritas aos corpos, dessa maneira, ao recriar uma imagem, como a de Marilyn Monroe, muitas vezes sua representação atinge tons sarcásticos e grosseiros (FABRIS, 2015) em virtude da artificialidade. Isso pode ser percebido através do exagero presente nas fotografias, o que confere uma estética camp, composta por imagens surreais, forjadas, mostrando assim o artifício e a construção arbitrária por de trás das normas sociais (BALIEIRO, 2014).

A imitação da personagem em questão coloca a masculinidade/feminilidade canônica em jogo, mostrando-as como construções interpeladas histórica e socialmente, já que o artista elabora todo um aparato a fim de produzir um sexo biológico/ gênero que por ora pode não ser o seu. Assim é importante pensar que cada um de nós possui comportamentos institucionalizados historicamente como masculinos ou femininos, independentemente do sexo biológico. Com isso pode-se compreender que o gênero encontra-se associado às normas e às convenções culturais que variam no tempo e nas sociedades (MISKOLCl, 2012, p. 32). Também deve-se levar em consideração que o gênero nem sempre se consolidou de maneira coerente/consistente, assim é necessário compreender o gênero relacionado às intersecções políticas e culturais que o produzem (BUTLER, 2016) e o normalizam.

Assim quando o/a artista constrói sua obra, ele/a também constrói um gênero e uma identidade que serão explorados pela personagem que irá representar. Esse gênero (masculinidade/feminilidade) criado pelo artista nada mais é do que uma artificialidade que o permite atuar a fim de representar as personagens, entretanto não é apenas ao compor suas obras que o gênero é uma construção. Seu processo constitutivo é cultural, o gênero é aprendido e imposto ao sexo, daí pode se compreender o gênero como um significado cultural assumido pelo corpo sexuado (BUTLER, 2016). O gênero é engendrado através de um processo artificial que constitui as identidades a fim de normatizá-las e hierarquizá-las. Tanto o processo artístico de Morimura quanto de outras/os artistas, como as drags, denunciam a construtividade dos gêneros e as identidades definidas e decididas até mesmo antes do nascimento, indicando qual seria o caminho socialmente desejado que tal indivíduo deveria seguir (LOURO, 2004), caminho esse que é pautado através de inúmeras instituições de regulação e vigilância, ou bem, dos Aparelhos Ideológicos de Estado $^{5}$ - como chama Louis Althusser (1988), sendo eles igreja, família, escola, sindicato, mídia, sistema jurídico, trabalhista e hospitalar - essas instituições, através do poder, criam um sistema de vigilância o qual atua de maneira normalizadora, disciplinando e regulando a vida dos indivíduos, estabelecendo e impondo regras ${ }^{6}$ sociais como a heterossexualidade compulsória (RUBIN 1989), o sistema binário, o gênero e sexo como biologicamente

\footnotetext{
5 Entende-se que Louis Althusser não é um filósofo queer, mas relaciono suas teorias e entendo que as instâncias de regulação identitária, social, política e sexual são pautadas também pelos Aparelhos Ideológicos de Estado. De maneira que os Aparelhos Ideológicos de Estado fortificam a construção/imposição de normas que dão continuidade ao sexo-gênero-desejo, colocando-os em conformidade. Assim os Aparelhos Ideológicos de Estado atuam na vigilância e doutrinação para a manutenção das normas dominantes.

6 Os Aparelhos Ideológicos de Estado servem como mecanismo de dominação da população, servindo como método de controle da vida humana, principalmente em relação a questões políticas e financeiras. Althusser (1988) aborda principalmente a relação da luta de classes entre Estado, classe dominante e classe operária. Aqui, parto das ideias de Althusser para perceber como o modelo hegemônico se consolidou, sendo instituído através do sistema de vigilância que é composto por tais instituições.
} 
associados. Nesse sentido, posicionar-se através de uma abordagem queer é resistir a essas estruturas de vigilância e normalização (RODRíGUEZ, 2003). Esse sistema é uma grande rede de vigilância, pode-se quiçá compará-lo ao panóptico, ao qual Michel Foulcault se refere em Vigiar e Punir (1975). É preciso vigiar os indivíduos durante todo o tempo, bem como devem ser submetidos a uma pirâmide perpétua de olhares (FOUCAULT, 2016, p. 182)7. Pensar a vigilância e suas possibilidades assusta, ainda mais ao pensar nela hoje, que se encontra de maneira contínua e ampliada pelas redes sociais, sendo difusa e diversa em suas formas de regulação e controle; de modo que as instituições se permitem além de controlar, ditar normas, padrões de pureza, sanidade e insanidade se multiplicam constantemente (LOURO, 2004). A disseminação da vigilância se deve ao fato da inserção das mídias na vida social do indivíduo contemporâneo.

A construção, o gênero, as identidades pré-determinadas são pontos que Morimura trabalha com um aspecto camp, não se mostrando como uma forma natural de sensibilidade (SONTAG, 1987), mas como uma artificialidade proposta pela cultura. O camp ainda está relacionado à cópia, à imitação que ironiza o verdadeiro/ original, o dominante. Uma imitação exagerada de algo, como as drag queens, por exemplo, que possuem uma feminilidade que é diferente daquela da mulher cis. As drag queens optam por uma feminilidade exacerbada, maquiagem pesada, sapatos altíssimos, roupas pomposas, glamourosas, um exagero intencional da feminilidade atribuída a mulheres cis. Esse simulacro, essa imitação torna o camp uma cópia, sendo assim marginalizado, situando-se no intermédio entre a alta e a baixa cultura (SOUZA, 2014), não sendo bom o suficiente para ser considerado algo digno de seriedade.

Mais evidente ainda nas obras de Yasumasa Morimura, as construções identitárias se mostram extremamente artificiais e construídas já que, ao analisar a maquiagem exagerada e cenários construídos, tudo se mostra evidentemente falso (FABRIS, 2015), camp pela sua paródia, representação e teatralidade dramática (SONTAG, 1987). Inclusive pelo fato de ao apresentar um corpo feminino, o artista desenvolve uma feminilidade que não necessariamente é aquela atribuída às mulheres do sexo biológico feminino ${ }^{8}$, mas não por isso menos feminino. A obra Doublonnage (Marcel) permite pensar a feminilidade como uma performance, assim como a filósofa Judith Butler (1996), pioneira nos estudos queer, explica através do conceito de performatividade usando como exemplo a teatralidade das drag queens.

Devido às construções/representações identitárias extravagantes, vejo a produção de Yasumasa Morimura pertencente à estética camp, já que existe um apreço às artificialidades e pelo exagero intencional. E por tratar-se de um artista que produz obras através da apropriação, um método de produção que, em visões mais conservadoras, pode ser considerado como uma antiarte, ou uma manifestação pautada no plágio, mas 7 A vigilância constante a qual Michel Foulcault (1975) se refere me faz lembrar a obra 1984, de George Orwell (1949), onde os cidadãos são submetidos a uma onipresente vigilância que reprime aqueles/as que não funcionam conforme o sistema.

8 De acordo com Paul B. Preciado (2009) a representação hiperbólica da masculinidade ou da feminilidade assume ainda mais um caráter artificial, já que ambos os dois conceitos estão sendo teatralizados, não atendendo aos significados socialmente aceitos dos termos. Produzindo assim novas masculinidades e novas feminilidades, que não somente se inscrevem em corpos consonantes com os gêneros estipulados, mas formam também a masculinidade feminina e a feminilidade masculina, uma vez que "supondo a estabilidade do sexo binário não decorre daí que a construção do termo 'homens' se aplique exclusivamente a corpos masculinos, ou que o termo 'mulheres' interprete somente corpos femininos" (BUTLER, 2016). Sobre isso também discorreu Guacira Lopes Louro (2004): veja-se o caso drag queen e sua "imitação" do feminino, em qual feminino ela busca suas referências? Não seria uma imitação fiel do feminino e da sua feminilidade, seria outro tipo de feminilidade que fora assim construída, com o apreço à ousadia, à extravagância, à artificialidade dos gêneros. A drag queen indica a proximidade da fronteira entre os gêneros, ela exibe a transitoriedade das identidades e dos gêneros regulados (Idem, ibidem), bem como a instabilidade das fronteiras binárias ao produzir novos corpos e novas subjetividades. 
assim como Rosa María Blanca (2011), aqui não se procura "privilegiar um trabalho sobre outro, o original sobre a cópia". Assim, a apropriação utilizada por Yasumasa Morimura ao produzir suas obras pode ser considerada uma linguagem marginal, e isso a aproxima ainda mais do camp. Já que nada é muito original, bom demais ou não suficientemente marginal pode ser camp, ou ainda a predileção por coisas que não são (SONTAG, 1987), que apenas aparentam ser, imitações de algo considerado real/original.

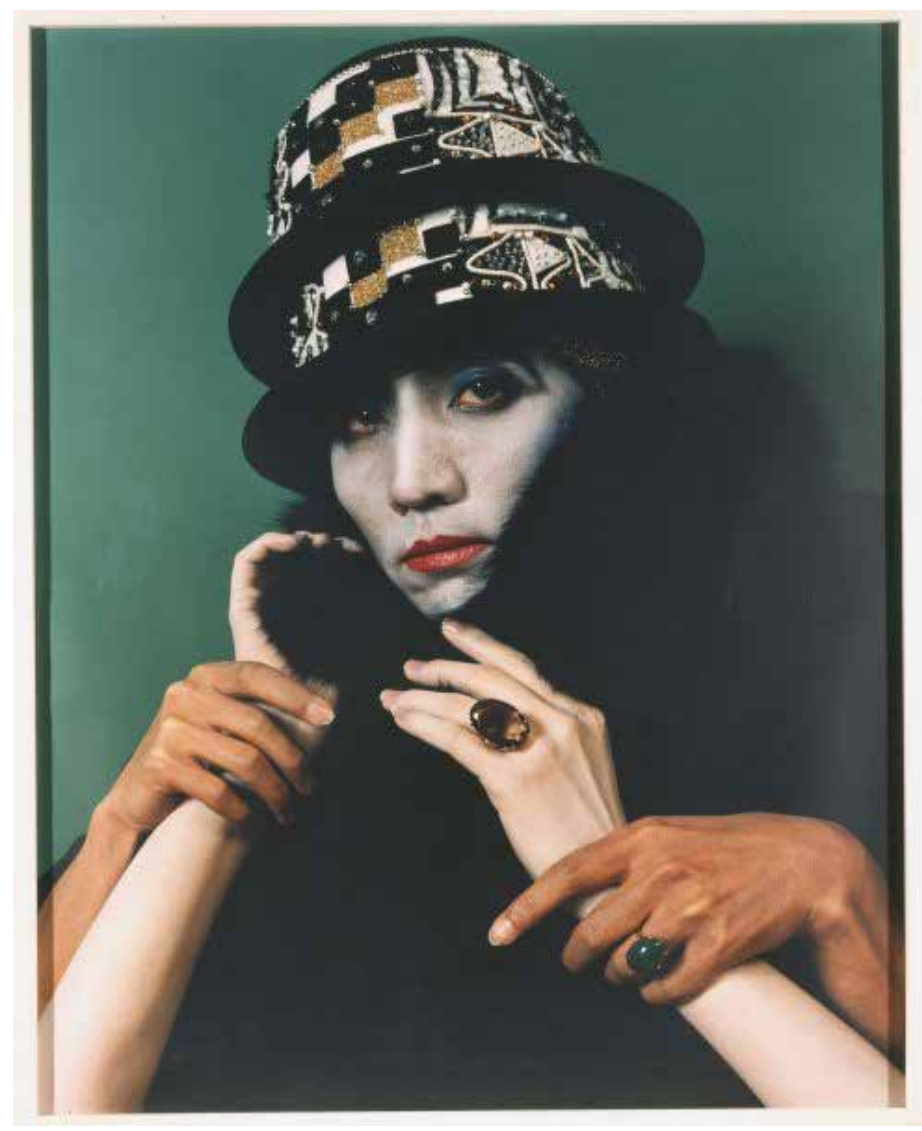

Fig. 2 - Yasumasa Morimura, Doublonnage, Marcel, 1995 Fotografía en color, 150 x $120 \mathrm{~cm}$. Fonte: http://www.museoreinasofia.es/sites/

\section{Considerações Finais}

A produção artística de Cindy Sherman e de Yasumasa Morimura abordam a multiplicidade identitária dos indivíduos contemporâneos. Observou-se, neste artigo, que os paradigmas identitários se transformaram em decorrência do avanço da globalização, influenciando na transitoriedade dos sujeitos. A abordagem analítica queer permitiu o distanciamento das técnicas reguladoras de corpos e comportamentos, abrindo margem para uma pesquisa dos processos de subjetivação, rompendo com premissas identitárias alicerçadas em paradigmas do sujeito iluminista, explorando as possibilidades (des)identitárias da contemporaneidade. A abordagem queer propõe leituras plurais nas obras de arte, uma vez que ela instigou à desconstrução das identidades fixas e destacou que a constituição dos sujeitos e das identidades opera na artificialidade através de processos de inteligibilidade.

Os resultados das análises que apresento aqui se constituem como uma das inúmeras possibilidades de leitura e de interpretação. Não pretendo atribuir valores 
absolutos e nem estabilizadores às obras de arte e nem aos conceitos utilizados. Penso que a multiplicidade de leituras é primordial na arte, uma vez que ela opera na democracia. Os conceitos e as obras analisadas se inserem no trânsito e na pluralidade, não busco construir um discurso único e nem uma verdade incontestável, busco caminhos plurais e abertos para que as interpretações não se restrinjam, mas para que se ampliem. Proponho uma inquietação a um assunto que exige sensibilidade, ainda mais no momento de discussão artística atual.

O queer mostrou-se como um termo flexível, constantemente ressignificado, desde suas primeiras utilizações, quando foi apropriado e subvertido conceitualmente, passando não mais a operar como humilhação, mas como empoderamento individual e coletivo. Sua atuação se distancia das normas de gênero, de modo que possibilita a sua desestabilização. Cindy Sherman e Yasumasa Morimura trouxeram obras onde essas mudanças de sujeito são perceptíveis, mostrando as máscaras que os sujeitos sociais usam no dia-a-dia, enfatizando a artificialidade do real e do sistema identitário.

O sujeito do autorretrato foi problematizado, abrindo discussão para as possibilidades de si em frente à câmera. $O$ trânsito identitário é comum à contemporaneidade, dessa maneira os autorretratos podem abordar uma multiplicidade de identidades presentes no mesmo corpo em diferentes momentos. Neste sentido, o sujeito é compreendido como um migrante e o que importa não é a chegada a uma identidade final, mas o percurso de (des)construção identitário.

Nas obras de Yasumasa Morimura o camp se insere como uma estética que é pautada pelo exagero, pela ironia, pela dramatização e pela metáfora. A ironia presente no camp permite questionar e parodiar o sistema dominante, problematizando a sua suposta naturalidade e soberania. Neste sentido, as imposições sociocomportamentais são parodiadas afim de mostrar que elas se constroem através de uma sociedade de poder que se baseia no pretexto da coesão de gênero e sexo biológico, invalidando todos os indivíduos que não apresentam coerência entre o gênero e o sexo. No camp há a intenção de ironizar o dominante a fim de desconstruí-lo para compreendê-lo como uma artificialidade socialmente imposta.

Neste sentido, este artigo abordou, através das obras de Cindy Sherman e Yasumasa Morimura, as transformações identitárias da contemporaneidade. Alertando para os processos de (des)construção e (des)identificação dos sujeitos, que se posicionam como efêmeros e transitórios, explorando as possibilidades de si e do outro no devir identitário.

\section{Referências}

ANZALDÚA, G. Borderlands/La Frontera. San Francisco: Aunt Lute Books, 1987.

ARCHER, M. Arte contemporânea: uma história concisa. São Paulo: Martins Fontes, 2012.

ALTHUSSER, L. Ideología y aparatos ideológicos del estado. Buenos Aires: Nueva Visión, 1988. 
BALIEIRO, F. F. Carmen Miranda entre os desejos de duas nações: cultura de massas, performatividade e cumplicidade subversiva em sua trajetória. UFSCar: Tese de Doutorado, 2014.

BAUMAN, Z. Ensaios sobre o conceito de cultura. Rio de Janeiro: Jorge Zahar Editor, 2012.

BLANCA, R. M. Arte a partir de uma perspectiva queer. UFSC: tese de doutorado, 2011.

BOURCIER, MH S. Queer Zones 3: identités, cultures et politiques. Paris: Éditions Amsterdam, 2011.

BUTLER, J. Problemas de gênero: feminismos e subversão da identidade. Rio de Janeiro: Civilização Brasileira, 2016.

DEMPSEY, A. Estilos Escolas e Movimentos. São Paulo: Cosac Naify, 2010.

FABRIS, A. Cindy Sherman ou de alguns estereótipos cinematográficos e televisivos. Revista Estudos Feministas, Florianópolis , v. 11, n. 1, p. 61-70, 2003.

FABRIS, Annateresa. Uma" magnífica presa": representações visuais de Marilyn Monroe. Anais do Museu Paulista: História e Cultura Material, v. 23, n. 1, p. 11-28, 2015.

FOUCAULT, M. Surveiller et punir. Paris: Gallimard, 1975.

FOUCAULT, M. O que é um autor? Lisboa: Passagens, 1992.

FOUCAULT, M. Microfísica do poder. São Paulo: Paz e Terra, 2016.

HALL, S. A identidade cultural na pós-modernidade. Rio de Janeiro: Lamparina, 2015.

JONES, A. Tracing the Subject with Cindy Sherman. In: CRUZ, Amada et al. Cindy Sherman. London: Thames and Hudson, 1997.

LOURO, G. L. Um corpo estranho: ensaios sobre sexualidade e teoria queer. Belo Horizonte: Autêntica, 2004.

MISKOLCI, R. Teoria Queer: um aprendizado pelas diferenças. Belo Horizonte: Autêntica, 2012.

ORWELL, G. 1984. 17. ed. São Paulo: Nacional, 1984. 
PACHECO, M. E. V. A pintura do autorretrato contemporâneo em Portugal: breve panorâmica. Diacrítica, Braga, v. 26, n. 3, p. 93-130, 2012.

PELÚCIO, Larissa. Breve história afetiva de uma teoria deslocada. Florestan, v. 1, p. 26-45, 2014.

PRECIADO, P. B. Género y performance: 3 episodios de un cybermanga feminista queer trans. Debate feminista, v. 40, p. 111-123, 2009.

RODRÍGUEZ, J. M. Queer Latinidad: Identity practices, discursive spaces. New York: New York University Press, 2003.

RUBIN, G. Reflexionando sobre el sexo: notas para una teoria radical de la sexualidad. In: VANCE, C. Placer y peligro. Explorando la sexualidade femenina. Madrid: Ed. Revolución, 1989.

SONTAG, S. Notas sobre o Camp. In: Contra a interpretação. Porto Alegre: LPM, 1987.

SOUZA, R. O que o camp tem a nos dizer em 2014. In: Anais do 23ํ Encontro da ANPAP, 2014.

TADEU, T. Nós ciborgues: o corpo elétrico e a dissolução do humano. In: HARAWAY, D; KUNZRU, H; TADEU, T. A antropologia do ciborgue: as vertigens do pós-humano. Belo Horizonte: Autêntica, 2016. 